\title{
Essential fructosuria
}

INSERM

\section{Source}

INSERM. (1999). Orphanet: an online rare disease and orphan drug data base. Essential fructosuria. ORPHA:2056

Essential fructosuria is a rare autosomal recessive disorder of fructose metabolism (see this term) caused by a deficiency of fructokinaseenzyme activity. It is characterized by elevated fructosemia and presence of fructosuria following ingestion of fructose and related sugars (sucrose, sorbitol). Essential fructosuria is clinically asymptomatic and harmless. Dietary restriction is not indicated. 